\title{
ESTRATÉGIAS DE VISIBILIDADE DE CONDOMÍNIOS DE BLOGS DE CIÊNCIA
}

\author{
Visibility strategies of science blogs networks \\ Estrategias de visibilidad de condomínios de blogs de ciencia
}

Natália Martins Flores

Jornalista e pesquisadora de Comunicação/Universidade Federal de Pelotas

nataliflores@gmail.com

Maria Ivete Trevisan Fossá

Docente e pesquisadora de Comunicação/Universidade Federal de Santa Maria

fossa@terra.com.br

\section{Resumo}

Investigam-se as estratégias de visibilidade dos condomínios de blogs de ciência Science Blogs Brasil e Blogs de Ciência da Unicamp. A partir da análise dos elementos textuais, arquiteturais e iconotextuais de sua cenografia digital, mostra-se que esses espaços constroem estratégias de visibilidade para um sujeito coletivo - representado pela figura do condomínio e da instituição de pesquisa - e para um sujeito individual, de cientistas blogueiros e laboratórios de pesquisa. $O$ sujeito coletivo constrói sentidos de uma comunidade participativa, no Science Blogs Brasil, e de uma comunidade institucional, no Blogs de Ciência da Unicamp, cujas fronteiras são bem delimitadas.

Palavras-chave: Blogs de ciência. Divulgação científica. Estratégias de visibilidade.

\begin{abstract}
We investigate the visibility strategies of the condominiums of science blogs Science Blogs Brasil and Blogs de Ciência da Unicamp. From the analysis of the textual, architectural and iconotextual elements of its digital scenography, it is shown that these spaces construct visibility strategies for a collective subject - represented by the condominium figure and the research institution - and for an individual subject, of bloggers and research labs. The collective subject builds meanings of a participatory community in the Science Blogs, and of an institutional community with well delimited boundaries in the Blogs de Ciência da Unicamp.
\end{abstract}


Key words: Science Blogs. Science Communication. Visibility strategies.

\section{Resumen}

Se investiga las estrategias de visibilidad de los condominios de blogs de ciencia Science Blogs Brasil y Blogs de Ciencia de la Unicamp. A partir del análisis de los elementos textuales, arquitectónicos e iconotexuales de su escenografía digital, se muestra que esos espacios construyen estrategias de visibilidad para un sujeto colectivo - representado por la figura del condominio y de la institución de investigación - y para un sujeto individual, de científicos bloggers y laboratorios de investigación. El sujeto colectivo construye sentidos de una comunidad participativa, en el Science Blogs Brasil, y de una comunidad institucional, en el Blogs de Ciencia de la Unicamp, cuyas fronteras están bien delimitadas.

Palabras clave: Blogs de ciencia. Divulgación científica. Estrategias de visibilidad.

\section{INTRODUÇÃO}

As formas de visibilidade de indivíduos e instituições respaldam-se, cada vez mais, na exposição de si no ciberespaço, por meio do uso de dispositivos tecnológicos e plataformas sociais digitais. Essa presença na rede permite à internet se tornar um espaço importante para a construção de identidades de instituições e visibilização de causas de movimentos sociais cuja repercussão nos meios de comunicação tradicionais ainda é escassa. No campo da divulgação científica, vemos surgir uma série de iniciativas interessadas em visibilizar e fazer repercutir os discursos sobre ciências na rede. Diversos blogs, páginas de Facebook e canais no Youtube articulam-se formando uma ambiência de divulgação científica no ciberespaço.

Neste artigo refletimos sobre os blogs de divulgação científica como espaços estratégicos de construção de visibilidade para instituições científicas e cientistas. Como modo de exemplificar o nosso argumento, apontamos as estratégias de visibilidade utilizadas pelos condomínios de blogs de ciência Science Blogs Brasil e Blogs de Ciência da Unicamp para moldar o seu discurso. Utilizamos o aporte teórico-metodológico da análise do discurso, nos respaldando no conceito de cenografia digital, de Maingueneau (2014), para mostrar como a conformação do espaço discursivo do enunciador e as formas de disposição dos elementos tecnodiscursivos da plataforma articulam-se na produção de visibilidade para a comunidade blogueira, a instituição e o cientista. 


\section{Divulgação científica e visibilidade}

As práticas de se fazer ver do discurso científico e da ciência tornam-se cada vez mais comuns na contemporaneidade. Elas ganham forma nos produtos midiáticos de divulgação científica, cuja função é de disseminar informações de ciência e tecnologia para um público numeroso e leigo no assunto, democratizando o conhecimento científico gerado nos centros de pesquisa. Pesquisadores referem-se, então, a um processo de simplificação ou de recodificação da linguagem, que transforma a linguagem hermética da ciência, entendida por poucos, em uma linguagem mais popular (CALVO HERNANDO, 1992; BUENO, 2010).

As transformações na linguagem implicadas na divulgação científica posicionam-na no entremeio entre o universo científico e a vida cotidiana, sendo a principal agenciadora das relações entre ciência e sociedade. Esse agenciamento ganha importância pela centralidade que a instância midiática passa a ocupar no cenário da midiatização. Antes de representar realidades de campos sociais externos, a mídia expande suas lógicas de funcionamento a outros processos sociais, ditando uma nova racionalidade e cultura para os campos sociais (FAUSTO NETO, 2008). A apropriação dessas lógicas torna-se condição para que as práticas científicas sejam reconhecidas socialmente.

As imbricações existentes entre o campo midiático e o científico podem ser observadas nos processos de incorporação de mecanismos midiáticos pelo campo científico, como a utilização recorrente de assessores de imprensa e um apreço cada vez maior por parte dos cientistas pela visibilidade midiática. Esses indivíduos passam a utilizar os espaços dos meios de comunicação para promover suas pesquisas e obter financiamentos e apoio para seus projetos. Ao observar esse cenário, Castelfranchi (2010) comenta que a divulgação científica passa a fazer parte do próprio metabolismo do sistema científico, adquirindo papel estratégico de manutenção do modelo de produção científica.

O processo de divulgação científica torna-se eficiente justamente pelo fato de instaurar regimes de visibilidade para a ciência, tornando-a visível a um maior número de pessoas. A partir de John Thompson (2008), pensamos nesses regimes como relacionados ao uso que os sujeitos fazem dos dispositivos midiáticos e tecnologias de comunicação. Para o pesquisador, ao promover novos campos de ação e interação entre as pessoas, os meios de comunicação instauram formas distintas de visualidade, que variam conforme a fase social analisada. Antes do desenvolvimento da imprensa, por exemplo, fazer-se visível dependia da copresença física, ou seja, do compartilhamento de uma situação espaço temporal com o outro indivíduo. Mais adiante, os meios de comunicação de massa fazem emergir uma visibilidade mediada 
desvinculada das características da copresença do aqui e agora. As formas de se fazer visível passam, então, a assumir as especificidades de cada meio de comunicação e passam a ser moldadas pelas estratégias de enquadramento e angulação do discurso midiático (THOMPSON, 2008).

No campo da divulgação científica, os regimes de visibilidade evoluíram conforme os regimes apontados por Thompson. A interação face-a-face dos debates sobre ciência e a visibilização copresencial da ciência promovidos nos salões femininos do final do século XIX passam a sofrer mediações tecnológicas dos meios de comunicação de massa, cujo discurso molda imagens pré-formatadas da ciência e do cientista. Outro passo importante deu-se a partir da liberação do polo de emissão e da emergência da cultura da participação, caracterizada pela produção de conteúdo por amadores (SHIRKY, 2011). O uso de blogs e mídias sociais possibilita ao cientista produzir sua própria imagem, dispensando a mediação jornalística.

As práticas blogueiras da comunidade científica são vistas como estratégicas para a produção de visibilidades para seus atores. De forma geral, compartilha-se a ideia de que os blogs são dispositivos de exposição e de promoção de si para o cientista (FLORES, 2016), que se vê obrigado a assumir o papel estratégico de comunicador de ciência diante de um contexto acadêmico competitivo (FAGUNDES, 2013). A visibilidade de instituições poderia vir relacionada às imagens discursivas dos cientistas blogueiros, já que esses indivíduos pertencem a instituições de pesquisa específicas. A partir desse pressuposto, torna-se interessante investigar as estratégias de visibilidade produzidas nestes dispositivos.

\section{Olhares sobre os condomínios de blogs científicos}

Nosso estudo deteve-se na análise dos condomínios de blogs de divulgação científica Science Blogs Brasil e Blogs de Ciência da Unicamp. ${ }^{1}$ A escolha por analisar esses espaços se deve ao fato deles serem as redes de blogs com mais visibilidade no sistema de busca do Google, utilizando as palavras-chave "blogs de ciência" e "condomínio de blogs". A partir da observação dos sites dos condomínios, de posts de blogs agregados a eles e de postagens nas suas páginas sociais do Facebook e do Twitter, pudemos descrever suas estratégias de visibilidade. Também nos baseamos em textos de apresentação dos condomínios nos seus sites, que explicitam suas funções e lógicas de organização. Utilizamos, especificamente,

\footnotetext{
${ }^{1}$ Os sites dos condomínios estão disponíveis em: www.scienceblogsbrasil.com.br e http://www.blogs.ea2.unicamp.br/pt_BR/. Acesso em 30 de janeiro de 2017.
} 
quatro textos deste tipo, sendo três do condomínio Blogs de Ciência da Unicamp e um da rede Science Blogs Brasil. ${ }^{2}$

O Science Blogs Brasil é uma rede de blogs que surgiu em 2008 e possui cerca de 50 blogs de autoria heterogênea formada por professores pesquisadores, alunos de pósgraduação, jornalistas ou pessoas interessadas em ciência sem nenhuma formação científica específica. Trata-se de blogs independentes que não se vinculam a uma instituição de pesquisa específica. O condomínio Blogs de Ciência da Unicamp, por outro lado, tem um caráter institucional, pois foi criado em novembro de 2015 por um órgão suplementar da Pró-Reitoria de Graduação da Unicamp, baseado na necessidade de agrupar blogs de pesquisadores e docentes da universidade em uma única plataforma. O condomínio possui cerca de 20 blogs de autoria de pesquisadores da Unicamp.

A formação da identidade dos condomínios dá-se por meio de estratégias de visibilidade delineadas com o objetivo de tornar seu espaço visível no universo da blogosfera científica. A partir da perspectiva teórica de Paveau (2012; 2013), observamos que essas estratégias remetem ao espaço de enunciação criado pelo enunciador dos blogs por meio da imbricação de recursos linguísticos e tecnodiscursivos, que elaborariam o discurso da internet no seu conjunto. Essa configuração daria forma ao que Maingueneau $(2014 ; 2013 ; 2008)$ denomina de cenografia, processo de encenação do discurso, que configura um mundo ao definir os status do enunciador e do coenunciador, ao mesmo tempo em que instaura um tempo e lugar para a enunciação. Na web, a cenografia seria composta por elementos iconotextuais (o site como conjunto de imagens em uma tela); arquiteturais (o site constitui-se numa rede de sites agenciados de determinada maneira) e procedurais (cada site traria instruções destinadas a um usuário).

Nossa análise focou-se: a) nas formas de posicionamento enunciativo do enunciador, que formam a cenografia verbal, por meio da configuração dos textos de apresentação dos condomínios e dos blogueiros; b) nos elementos iconotextuais, de disposição visual do conjunto de imagens e módulos heterogêneos que formam a página inicial dos condomínios e os modos de apresentação dos blogueiros e blogs e c) nas formas arquiteturais de conexão entre o site do condomínio e suas páginas nas mídias sociais Facebook e Twitter.

Em ambos os condomínios, observamos que esses elementos formam, no seu conjunto, estratégias de visibilidade: 1) de um sujeito coletivo, que acentuam as marcas do

\footnotetext{
${ }^{2}$ Os textos estão disponíveis em: http://www.blogs.ea2.unicamp.br/pt_BR/como-participar/; http://www.blogs.ea2.unicamp.br/pt_BR/institucional/; http://www.blogs.ea2.unicamp.br/pt BR/equipe-2/ e http://scienceblogs.com.br/sobre/. Acesso em 30 de janeiro de 2017.
} 
condomínio e da instituição de pesquisa e 2) de um sujeito individual, que moldam conteúdos de autopromoção do blogueiro ou do seu laboratório de pesquisa. Os dois tipos de estratégia encontram-se entrelaçados no funcionamento dos condomínios e pretendem legitimar as atividades de divulgação exercidas pela comunidade de blogueiros. A seguir, pontuamos algumas observações sobre essas construções discursivas.

\subsection{A construção de uma comunidade}

As estratégias de visibilidade do sujeito coletivo concentram-se na formação da identidade das comunidades de blogueiros - da plataforma dos condomínios - e da Universidade Estadual de Campinas, no caso dos Blogs de Ciência da Unicamp. Elas estão presentes na configuração iconotextual de disposição dos elementos na página principal dos condomínios e em marcas discursivo textuais dos seus textos de apresentação e das suas postagens de divulgação nas mídias sociais. A principal tática consiste em colocar o administrador do condomínio como enunciador, cuja função é explicitar as lógicas de funcionamento da rede. Esses enunciados constroem um sentido de comunidade em torno destes espaços, definindo quem pode ou não integrar a rede.

A identidade em torno da comunidade dos condomínios apresenta-se visualmente na página principal destas redes, a partir da disposição dos seus elementos. A presença da logomarca no template do site e de módulos com as postagens mais recentes dos blogs pertencentes ao condomínio e com os canais de YouTube dos seus blogueiros reforça o sentido de unidade e de vínculo entre os elementos desta rede (figura 1). Esse modo de disposição visual se faz presente nos dois condomínios analisados. 


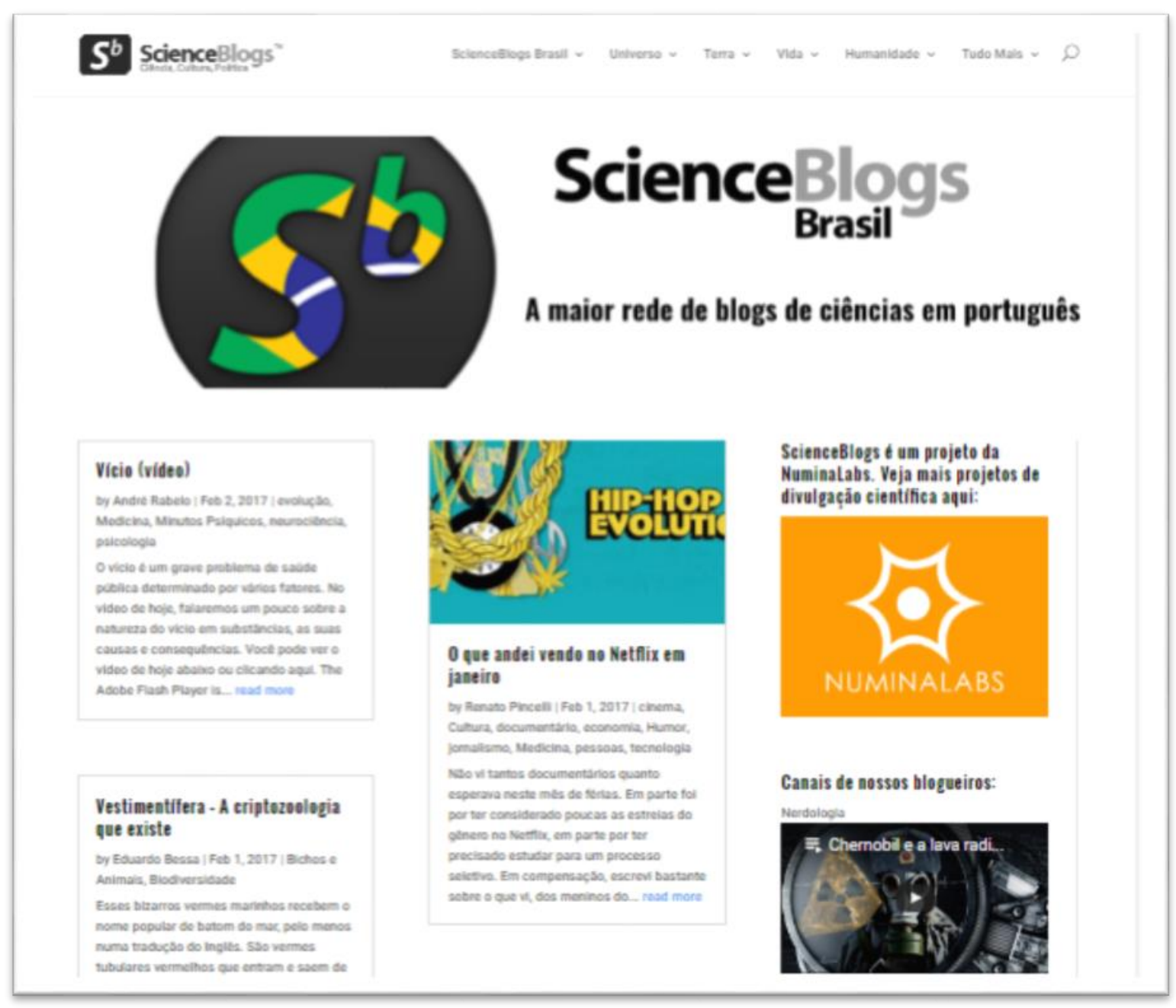

Figura 1 - Página principal do Science Blogs Brasil

Fonte: $\underline{w w w . s c i e n c e b l o g s . c o m . b r}$

No texto de apresentação do condomínio Science Blogs Brasil, o sentido de comunidade é construído por meio da explicitação da sua vinculação à rede Science Blogs e da sua trajetória de consolidação. O enunciador inicia seu texto apresentando a rede Science Blogs como "a maior rede de blogs de Ciências do mundo", numa tentativa de lhe conferir credibilidade e prestígio. Logo em seguida, cita-se o histórico desta rede, que começou em 2006 e tem condomínios de blogs de ciência em alemão, em inglês e em português, além de se citar o número de blogs presentes em cada uma de suas versões.

Parte-se, então, para uma descrição específica da versão brasileira e sua trajetória. Descreve-se que essa nasceu da associação do condomínio Lablogatórios, criado em 2008 por dois cientistas brasileiros, com a marca Science Blogs. Reforça-se no texto o crescimento do condomínio, que passou de um "projeto pessoal” para um profissional, já que agora ele também está vinculado a uma empresa de comunicação especializada em produção de 
conteúdo de divulgação científica. A profissionalização do condomínio aparece por meio do oferecimento de espaços de anúncio no portal, além de e-mails de contatos comerciais, técnicos e editoriais no Brasil e no mundo. Ela também vem acoplada a uma visibilidade internacional da iniciativa, que "ganhou proporções internacionais, unindo e potencializando uma comunidade de divulgadores científicos".

Assim como o trecho citado acima, observamos que o texto ressalta, em alguns momentos, o caráter de comunidade do condomínio. Uma das estratégias discursivas consiste no uso da primeira pessoa do plural para se referir ao enunciador, que cria a imagem de um coletivo de pessoas responsável por gerenciar o conteúdo e o sistema do condomínio (Exemplos 1 e 2). Constrói-se, assim, um sujeito coletivo imaginário, uma comunidade discursiva que partilha das mesmas práticas discursivas (MAINGUENEAU, 1997) - um "nós" em relação a "eles". Essa construção discursiva pretende incluir o interlocutor neste universo comunitário, quando, por exemplo, faz convites a ele para que se torne um futuro blogueiro (Exemplo 2):

Exemplo 1: Trabalhamos para que a comunidade formada em torno do ScienceBlogs Brasil atue na dispersão do pensamento científico, e ficamos à disposição para levar à frente projetos e iniciativas quebrando as barreiras que afastam nossa sociedade da Ciência. (ScienceBlogs, http://)

Exemplo 2: Se você já tem um blog de Ciência, entre em contato conosco. Estamos sempre buscando contribuições relevantes. Se você não tem um, pode criar usando um dos diversos serviços de weblogs grátis, como Blogger e WordPress ou enviar textos para serem publicados em nosso blog Tubo de Ensaios. (ScienceBlogs, http://)

Nos dois exemplos, podemos observar marcas de abertura do Science Blogs Brasil para a inclusão de outras iniciativas de divulgação científica (vide expressões como "ficamos à disposição" e "entre em contato conosco"). No exemplo 2, oferecem-se diversas maneiras do interlocutor participar da comunidade, por meio da criação de um blog de ciência que possa oferecer "contribuições relevantes" para a comunidade de blogueiros ou por meio do envio de textos para serem postados em um blog específico do condomínio. Essas marcas discursivas mostram o interesse do Science Blogs de aumentar a sua comunidade de blogueiros, fortalecendo a produção de conteúdo de ciência e a interação entre eles. 
Outra estratégia de construção de visibilidade em torno da comunidade Science Blogs consiste na manutenção dos blogs Raio-X e de perfis nas mídias sociais Facebook e Twitter $^{3}$ Esses canais servem como espaços de promoção da rede, trazendo dinamicidade à sua distribuição de conteúdo.

O blog Raio-X tem como proposta "revelar os bastidores do Science Blogs Brasil", por meio da divulgação de novidades sobre os blogs e blogueiros da rede. Mantido por seus administradores, o espaço expõe e promove os vínculos de comunidade do Science Blogs ao postar textos apresentando os novos blogs integrantes da rede e divulgando a participação dos seus blogueiros em eventos como a Campus Party. Esse vínculo é fortalecido e estendido para não blogueiros por meio da promoção de concursos culturais e atividades de interação entre os leitores e os blogueiros do condomínio. Um exemplo é o InterCiência, blogagem coletiva promovida pelo condomínio em 2013. ${ }^{4}$ Ela consistiu em um amigo oculto com o qual os divulgadores de ciência poderiam trocar textos e outros materiais sobre ciência. Uma rodada seria fechada a cada 12 textos inscritos no intercâmbio e caberia ao indivíduo que recebesse o conteúdo adivinhar o seu autor ou autora. Além de incentivar a produção do material, a iniciativa pretendia promover a interação entre os participantes.

O baixo número de postagens do blog Raio-X a partir de 2014 sugere que as atividades de promoção da comunidade migraram para o Facebook e o Twitter. Os administradores aproveitaram as ferramentas de compartilhamento de conteúdo multimídia destes canais para investir neles como espaço de visibilidade. Além de se divulgar e disseminar conteúdos produzidos para os blogs, utiliza-se o Facebook para a cobertura de eventos sociais científicos com a participação dos blogueiros. Essa cobertura faz-se por meio da publicação de conteúdos mais dinâmicos se comparado aos do blog Raio-X, como pequenos vídeos e notas do Facebook sobre palestras, produzidos especificamente para o canal. No Twitter, aposta-se no mesmo tipo de estratégia de divulgação, sendo que suas postagens são mais breves e interativas, vinculando-se também aos Twitter dos blogueiros e cientistas da rede. Por vezes, os twitts trazem links de conteúdos compartilhados no Facebook do condomínio, o que mostra a interação dinâmica entre essas plataformas.

A utilização de plataformas diversas permite ao Science Blogs construir uma ambiência em torno da sua marca. Isso ocorre pelo fato de os conteúdos e elementos

\footnotetext{
${ }^{3}$ Twitter e Facebook do ScienceBlogs Brasil disponíveis em: https://twitter.com/scienceblogsbr e https://www.facebook.com/scienceblogsbr/?fref=ts. O blog está disponível em: http://scienceblogs.com.br/raiox/. Acesso em 3 de fevereiro de 2017.

${ }^{4}$ Disponível em: http://scienceblogs.com.br/raiox/2013/01/interciencia/. Acesso em 4 de fevereiro de 2013.
} 
identitários presentes no site, no Facebook, no Twitter, nos blogs e no Youtube estarem conectados entre si, por meio das lógicas de compartilhamento destas plataformas. Os canais do Youtube produzidos pelos blogueiros da rede são disponibilizados no site e no Facebook do condomínio, assim como as postagens dos blogs são divulgadas no Twitter. Constrói-se uma ambiência interconectada de plataformas, o que permite o fortalecimento da comunidade responsável por alimentar esses espaços. Essa estratégia de visibilidade faz parte da atual ecologia dos cibermeios e é utilizada pelos dois condomínios analisados.

\subsection{A visibilidade institucional como estratégia}

As estratégias de visibilidade da comunidade do Blogs de Ciências da Unicamp diferem-se do condomínio Science Blogs por serem construídas em torno da identidade da Universidade Estadual de Campinas, instituição de seus blogueiros. A vinculação institucional aparece de forma explícita nos textos de apresentação do condomínio e de explicação de como participar da iniciativa, que podem ser acessados nos links "Institucional" e "Como Participar? ", na sua página principal. Essa configuração também é estabelecida pelo próprio nome escolhido para o condomínio e por algumas atividades e divulgações desenvolvidas no seu Facebook.

No texto "Institucional", discorre-se sobre a vinculação do projeto ao Espaço de Apoio ao Ensino e Aprendizagem, da Universidade Estadual de Campinas, cujo objetivo era "a criação de uma plataforma ou ferramenta que possibilitasse agregar blogs diversos de autoria de pesquisadores e docentes da Unicamp", seguindo exemplos de outros condomínios, como

o Science Blogs Brasil. No segundo texto, explica-se que "Toda a comunidade da Universidade Estadual de Campinas pode participar, mas somente docentes, pesquisadores, pós-doutorandos, doutorandos e mestrandos podem possuir um blog próprio". Assim, além de delimitar o escopo à comunidade acadêmica dessa universidade, também se delimita o grau de envolvimento do blogueiro com as pesquisas científicas, pois este deve ser, no mínimo, mestrando de algum Programa de Pós-Graduação da instituição (Blogs de Ciência da Unicamp, http://).

Temos uma comunidade com fronteiras bem delimitadas, representadas pelo espaço institucional da Unicamp, que estabelece quem pode participar e produzir conteúdo para a rede. Esse esforço de fortalecer a identidade institucional do projeto pode ser observado no fato de se exigir que o blogueiro iniciante faça um curso de formação em blogs de divulgação científica, ministrado semestralmente pelos laboratórios mantenedores do projeto. As 
informações sobre o curso e as formas de se inscrever estão no texto "Como Participar" e mostram o seu conteúdo programático, que abrange desde a introdução aos objetivos e funcionamento do projeto, a assuntos de divulgação científica até orientações de como mexer na ferramenta de publicação do blog.

O Facebook é utilizado pelo Blogs de Ciência da Unicamp para divulgar as postagens novas de seus blogs, além de servir de canal de disseminação da sua série de vídeos "Bloggers na rede", hospedada no seu canal de YouTube e produzida pelo Espaço de Apoio e Ensino e Aprendizagem (EA2). A série iniciou em meados de 2016 e é composta por vídeos curtos (2 a 5 minutos) em que os blogueiros da rede falam sobre a prática blogueira e sobre as atividades de divulgação científica, dando dicas de linguagem para blogs de ciência, entre outros assuntos. ${ }^{5}$ A iniciativa fortalece o senso de comunidade do grupo de blogueiros do projeto ao falar sobre a produção de blogs e expor seus blogueiros como participantes desta prática, vinculando-os à Unicamp.

Esses recursos geram, no seu conjunto, um caráter de profissionalismo para os blogs de ciência do grupo da Unicamp, já que eles são formalmente mantidos pela instituição, representada pela parceria entre o Laboratório de Estudos Avançados em Jornalismo, o Laboratório de Inovação Tecnológica Aplicada à Educação e o Espaço de Apoio e Aprendizagem. Segundo o texto de apresentação da iniciativa, esses laboratórios entram no projeto como forma de "agregar know-how em Divulgação Científica, Comunicação e Tecnologias", cujos conhecimentos são repassados para a comunidade de blogueiros nos cursos e, de certa forma, explicitados na série de vídeos "Bloggers na rede". Apesar de utilizar-se destas estratégias e mostrar que "fomenta, oportuniza, treina e dá suporte à iniciativa", a Unicamp opera um leve descolamento da sua imagem da do blogueiro ao salientar, no final do seu texto, que "os conteúdos dos blogs individuais são de responsabilidade total de seus autores".

\subsection{A visibilidade de cientistas e laboratórios}

As estratégias de visibilidade operadas pelos condomínios de blogs de ciência também procuram visibilizar as atividades de um sujeito individual, representado pelo cientista ou seu laboratório de pesquisa. Tratamos como sujeito individual justamente pelo enunciador ser o

\footnotetext{
${ }^{5}$ A série conta, atualmente, com três vídeos: "Que tipo de linguagem utilizar em Blogs de Ciência", "Dicas para Bloggers de Ciência" e "Importância da divulgação científica". Eles estão disponíveis em: https://www.youtube.com/channel/UCYh60CofP1szB5jTgsE-gcw. Acesso em 5 de fevereiro de 2017.
} 
próprio blogueiro e enunciar a partir do seu blog, diferenciando-se do administrador, cujos enunciados remetem à estrutura do condomínio e sua comunidade. Essas estratégias podem ser observadas nos posts dos blogs e nos textos de apresentação do blogueiro pertencentes a essas redes.

As estratégias de visibilidade individual remetem ao conteúdo dos posts e ao modo como o texto apresenta uma identidade para o blogueiro, vinculando-o ao universo da ciência. Para discorrer sobre esse processo, resgatamos os resultados da pesquisa de Gomes e Flores (2016), que categorizaram o conteúdo de 1.329 posts de 43 blogs de ciência. A partir de parâmetros como função comunicacional, papel dos participantes e configuração discursiva, as pesquisadoras chegaram às categorias de Cientista blogueiro Divulgador e Cientista blogueiro Protagonista, mostrando que esse último era o mais frequente no corpus (70\%). Essa posição discursiva tem o enunciador como centro do enunciado, utilizando estratégias de envolvimento e registros opinativos. Ela se desdobraria nas subcategorias de agenda/vitrine, diário, crítica e pessoal e traria o espaço dos blogs de ciência como propício para a construção e expressão do self do cientista (GOMES; FLORES, 2016).

Neste artigo, não pretendemos analisar detalhadamente os posts dos blogs dos condomínios, mas apenas indicar a possibilidade de estes atuarem na construção da imagem do cientista e do seu grupo de pesquisa. Procuramos nos respaldar nas subcategorias delineadas na pesquisa anterior de agenda/vitrine, cuja função consiste em "dar visibilidade ao cientista blogueiro ao servir de repositório de documentos, de atividades suas e de seu grupo de pesquisa ou alunos" (GOMES; FLORES, p.11), e de diário, que tem "textos que procuram refletir sobre a vida em laboratório e outras questões relacionadas à prática científica ou à ciência" (GOMES; FLORES, p.14). Nesse último caso, torna-se interessante observar que esses textos deixam ver uma imagem individual do enunciador, que se posiciona como cientista.

Vemos que as estratégias de visibilidade do indivíduo respaldam-se em um viés de autopromoção por meio da identidade dos cientistas blogueiros. Ela pode ocorrer por meio da divulgação das atividades do seu grupo de pesquisa, nos posts, e também nas formas do blogueiro se apresentar no blog. Vejamos, a seguir, exemplos deste segundo caso.

Exemplo 3: Roberta L. Drekener. Química industrial de formação, química orgânica de coração. Mestre em Química pela UFSM, doutora em Ciências pela Unicamp, pós doutora pela Unicamp e pelo Leibniz Institut of Plant Biochemistry (Alemanha). Se preocupa muito sobre como o mundo vê a ciência e mais ainda sobre o que a ciência faz pelo mundo. Atualmente 
está procurando seu lugar ao sol (para semear e colher frutos). (Blog Empirismos, hipóteses e teorias, http:// $)^{6}$

O texto de apresentação do exemplo 3 ressalta a trajetória acadêmica da cientista blogueira, pontuando a sua área de formação, sua titulação e as instituições em que realizou sua formação (UFSM, Unicamp) e onde está atualmente vinculada (Unicamp). O modo de construção do texto remete ao texto-resumo da Plataforma Lattes, do CNPq, espaço reservado ao acadêmico para discorrer sobre a sua formação profissional e área de atuação, além dos seus interesses de pesquisa e vínculo institucional. Neste sentido, vemos que a construção da imagem da blogueira perpassa o discurso acadêmico e sua vinculação institucional à Unicamp.

A vinculação institucional que aparece no começo do texto do exemplo 3, no entanto, é contrabalanceada ao longo do texto pela inserção de elementos informais típicos do universo da blogosfera. Assim, os enunciados marcados se afastam do perfil acadêmico tradicional da Plataforma Lattes ao humanizar a blogueira. Há uma carga de subjetividade nas palavras escolhidas para retratá-la, como alguém que "se preocupa muito sobre como o mundo vê a ciência e mais ainda sobre o que a ciência faz pelo mundo" e que "está procurando seu lugar ao sol (para semear e colher frutos)". O primeiro enunciado vincula a blogueira ao universo da divulgação científica, ao mostrar a sua preocupação na relação entre ciência e mundo. $\mathrm{O}$ segundo utiliza metáforas para falar da relação da blogueira com o seu lugar profissional.

A inserção de elementos informais da blogosfera e da vinculação institucional também pode ser observada no exemplo da figura 2. No perfil de apresentação selecionado, delineia-se uma vinculação institucional implícita através do selo da Plataforma Lattes, que direciona o usuário para o currículo Lattes do blogueiro. Convém mencionar que as estratégias de vinculação do sujeito à instituição no perfil de apresentação se limitam apenas à presença do link do Lattes, sendo que as universidades de formação ou de atuação deste sujeito não são mencionadas no texto. De outro modo, elementos informais e tecnodiscursivos como o endereço de e-mail, os selos de perfis do blogueiro nas redes sociais Facebook, Twitter, ResearchGate criam uma identidade virtual para esse sujeito, reforçando a sua presença na rede.

\footnotetext{
${ }^{6}$ Disponível em: http://www.blogs.ea2.unicamp.br/empirismoshipotesesteorias/roberta-l-drekener/. Acesso em 20 de fevereiro de 2017.
} 


\section{田圆因面}

$\angle$ samir elian

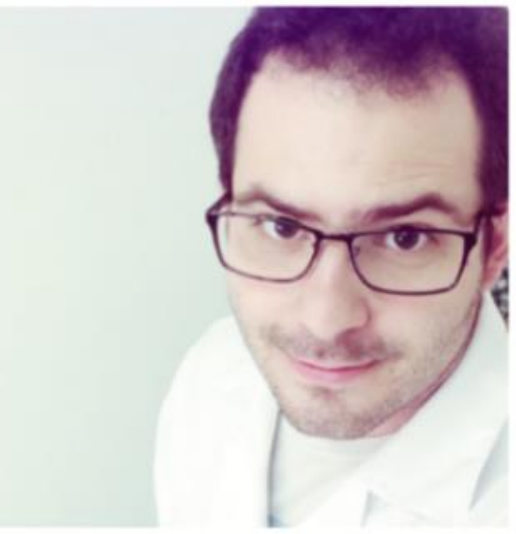

Um projeto de microbiologista que sabe que cultura não é apenas de bactérias - afinal, pode ser de fungos também! No mestrado, optou por charfurdar os campos da imunologia, investigando mecanismos de ação de uma bactéria probiótica em um modelo murino de colite ulcerativa. Pro doutorado resolveu mudar de ares, indo trabalhar com biologia molecular de uma bactéria patogênica.

- Entre em contato

samirescienceblogs.com.br

(9) $f$ Y RG

Figura 2 - Perfil de apresentação do blogueiro

A identidade virtual do blogueiro pode acentuar os elementos informais da blogosfera, misturando-os a elementos formais do universo científico. Na figura 3, por exemplo, os elementos formais são representados pelo selo da Plataforma Lattes e por trechos do texto de apresentação do cientista, que o descreve como um "biólogo, doutor em microbiologia e comunicador científico". Os informais ganham corpo na representação caricatural do cientista e em trechos do texto que o descrevem como um "curioso profissional que não consegue ler sobre uma coisa só", o que o distancia do perfil de cientista especialista em um tema específico, comum na comunidade acadêmica. 


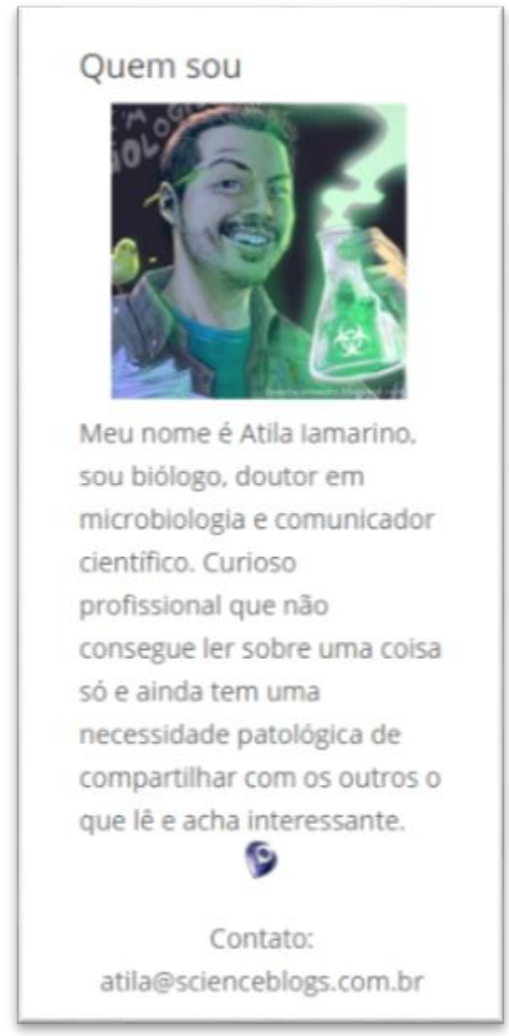

Figura 3 - Perfil de apresentação do blogueiro

Em alguns blogs, o espaço individual do cientista cede espaço para um coletivo de pesquisadores. Isso ocorre em blogs coletivos do Science Blogs e do Blogs de Ciência da Unicamp que possuem dois ou mais blogueiros. Esses espaços constroem a ciência como um projeto coletivo, cujos saberes e conhecimentos são produzidos pela troca de experiências e diálogos entre diversos cientistas, materializados na multiplicidade de enunciadores. No condomínio Blogs de Ciência da Unicamp, a construção discursiva da comunidade científica aparece nos blogs de grupos de pesquisa ou laboratórios da Unicamp. Esses dispositivos operam, então, na produção de visibilidade para os laboratórios de pesquisa da universidade.

Observemos como se dá esse processo na configuração do template do blog do Laboratório de Novas Tecnologias Aplicadas à Educação (figura 4). A formação de uma identidade visual para o laboratório da Unicamp consolida-se por meio do uso da sua logomarca, além da disponibilização de um link para acesso da revista produzida pelo LANTEC, logo abaixo do texto de apresentação. Os selos localizados no canto superior direito do template e o texto de apresentação do blog vinculam o laboratório ao condomínio de Blogs de Ciência da Unicamp e à Unicamp, por meio do Espaço de Apoio e Aprendizagem. 
Figura 4 - Produção de visibilidade para Laboratório da Unicamp

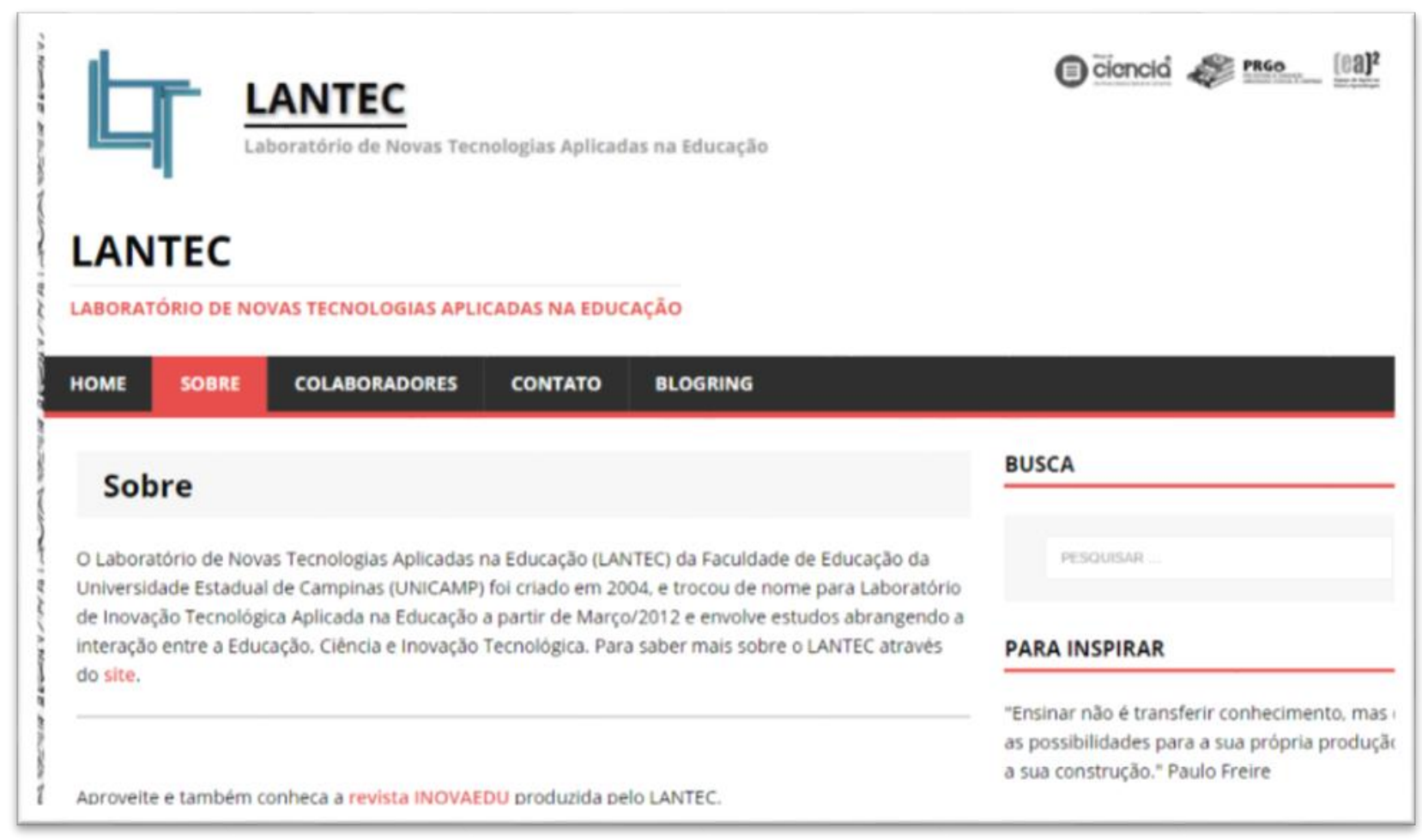

Figura 4 - Produção de visibilidade para Laboratório da Unicamp

Fonte: http://www.blogs.ea2.unicamp.br/lantec/

Como podemos observar nos apontamentos feitos até aqui, os condomínios de blogs de ciência constituem-se em espaços heterogêneos e complexos, produzindo espaços de visibilidade para sua comunidade, para as instituições científicas e para os cientistas. Em alguns momentos, vemos que os elementos tecnodiscursivos convergem na formação de estratégias de visibilidade para condomínios e instituições - no caso do condomínio Blogs de Ciência da Unicamp, cujos elementos institucionais utilizados na descrição e organização da rede parecem fortalecer a imagem de comunidade do condomínio. Em outros momentos, vemos a consonância entre elementos da imagem institucional e da imagem individual do cientista, quando o enunciador cita sua instituição de pesquisa ou seu Lattes no seu perfil de apresentação. A própria inserção dos blogs individuais de cientistas e laboratórios no condomínio já lhes fornece visibilidade frente a outros sites e blogs, seja por meio das estratégias de constituição da comunidade discursiva destas redes ou pela própria exposição nos sistemas de busca do Google, que elencam essas redes na sua primeira página de visualização. 


\section{CONSIDERAÇÕES FINAIS}

Neste artigo, empreendemos um olhar sobre as estratégias de visibilidade de condomínios de blogs de ciência. A partir do aporte teórico metodológico da análise do discurso, apontamos a construção de visibilidades para a comunidade discursiva dos condomínios, para o cientista blogueiro participante dessas redes e para a instituição da qual esses sujeitos fazem parte. As redes sociais e os blogs são utilizados pela comunidade científica como espaços de autopromoção. Neste contexto, os objetivos altruístas da divulgação científica de democratização do conhecimento parecem ficar num segundo plano diante da procura individualista dos cientistas por visibilidade.

A construção discursiva operada pelo Science Blogs Brasil fia-se no uso da visibilidade como estratégia de fortalecimento da sua marca. Dentre outros elementos, o condomínio se fixa na convocação e inclusão de novos membros para sua comunidade e na produção de estratégias de marketing científico, ao colocar-se como uma empresa que presta serviços de assessoria em divulgação científica. Cabe aqui questionar em que medida esse direcionamento comercial seria um caminho válido e agregador ou traria consequências negativas para as práticas contemporâneas de divulgação científica.

No Blogs de Ciência da Unicamp, trabalha-se diretamente com a legitimidade de quem fala. Elegem-se porta vozes da instituição, que precisam ter a titulação básica de mestrando para participar da comunidade de blogueiros. Ao profissionalizar a atividade blogueira, a Unicamp amplia a sua assessoria de imprensa, angariando porta vozes que participam de seus treinamentos e são acompanhados, de certa forma, pela equipe da Universidade. Essa estratégia permite à instituição ganhar presença virtual de qualidade com um custo reduzido. Os dois casos configuram-se como oportunidades de marketing em que as redes sociais são utilizadas para potencializar o valor das marcas dos condomínios e das instituições.

\section{REFERÊNCIAS}

CALVO HERnANDO, Manuel. Periodismo Científico. Madrid, Editorial Paraninfo, 1992.

CASTELFRANCHI, Yuri. Por que comunicar temas de ciência e tecnologia ao público? Muitas respostas óbvias... mais uma necessária). In: MASSARANI, Luísa. (coord.). Jornalismo e ciência: 
uma perspectiva ibero-americana. (pp.13-21), Rio de Janeiro: Fiocruz / COC / Museu da Vida, 2010.

BUENO, Wilson. Comunicação científica e divulgação científica: aproximações e rupturas conceituais. Revista Informação \& Informação, Londrina, v.15, n.esp. p.1-12, 2010.

FAGUNDES, Vanessa. Blogs de ciência: comunicação, participação e as rachaduras na Torre de Marfim. 2013. 180f. Dissertação (mestrado em Divulgação Científica e Cultural), Universidade Estadual de Campinas, Instituto de Estudos da Linguagem. Campinas, SP: 2013.

FAUSTO NETO, Antônio. Fragmentos de uma 'analítica' da midiatização. Revista Matrizes, São Leopoldo, n.2, p. 89-105, abr. 2008.

FLORES, Natália. Entre o protagonismo e a divulgação científica: as estratégias discursivas de constituição do ethos discursivo do cientista blogueiro em blogs de ciência brasileiros. Tese (Doutorado) 284f. - Universidade Federal de Pernambuco, Centro de Artes e Comunicação. Comunicação, 2016.

GOMES, Isaltina; FLORES, Natália. Categorização de blogs escritos por cientistas: uma proposta. Revista Famecos. Mídia, cultura e tecnologia. Porto Alegre, v.23, maio, junho, julho e agosto de 2016, p.1-18.

MAINGUENEAU, Dominique. Analyser les textes de communication. Paris: Armand Colin, 2014.

Genres de discours et web: existe-t-il des genres web? In: BARATS, C (org.) Manuel d'analyse du web. Paris: Armand Colin, 2013. p.74-93.

Cenas da enunciação. São Paulo: Parábola Editorial, 2008

. Novas tendências em análise do discurso. Tradução de Freda Indursky. 3. ed. Campinas: Editora da UNICAMP, 1997.

PAVEAU, Marie-Anne. Technodiscursivités natives sur Twitter. Une écologie du discours numérique. In: LIENARD, F. (coord.) Culture, identity and digital writing, Epistémè 9, Revue internationale de sciences humaines et sociales appliquées, Séoul : Université Korea, Center for Applied Cultural Studies, p. 139-176, 2013a pp. $95-115$.

Realité et discursitivé. D'autres dimensions pour la theorie du discours. Semen, 2012,

SHIRKY, Clay. A cultura da participação: criatividade e generosidade no mundo conectado. Rio de Janeiro: Zahar, 2011.

THOMPSON, John. A nova visibilidade. Matrizes. São Paulo, n.2, p.15-38, abril 2008. 
Jornalista, Doutora em Comunicação pela Universidade Federal de Pernambuco (UFPE), PósDoutora em Comunicação pela Universidade Federal de Santa Maria (UFSM). Integrante do grupo de pesquisa Comunicação Institucional e Organizacional (Poscom/UFSM) e Comunicação e Linguagem (PPGCOM/UFPE), ambos vinculados ao CNPq. Investiga temas relacionados à divulgação científica e a construção de imagens de cientistas em blogs e mídias sociais.

\section{Maria Ivete Trevisan Fossá}

Doutora em Administração pela Universidade Federal do Rio Grande do Sul. Professor Associado da Universidade Federal de Santa Maria, nível graduação, e docente e pesquisadora do Programa de Pós-Graduação em Comunicação da Universidade Federal de Santa Maria, vinculada à linha de Mídias e Estratégias Comunicacionais. Líder do Grupo de Pesquisa Comunicação Institucional e Organizacional (Poscom/UFSM). E-mail: fossa@terra.com.br.

Esta obra está licenciada sob uma Licença Creative Commons. 